\title{
Ethnic Identity: A Study of Construct Equivalence
}

\author{
Augustinus Supratiknya ${ }^{1}$ \\ Faculty of Psychology, Universitas Sanata Dharma
}

\begin{abstract}
This research aimed to examine the Multigroup Ethnic Identity Measure's (MEIM 1992) adequacy to explore Indonesian youth's ethnic identity. Hence MEIM 1992 was adapted into MEIM Indonesia through translation-back-translation method. Involving 448 ( 179 or $40 \%$ male and 269 or $60 \%$ female) students aged $17-28$ years (Mean $=19.87$; SD = 1.30) with different ethnic backgrounds in a private university in Yogyakarta as respondents, EFA with SPSS showed that the MEIM Indonesia measured one factor as MEIM 1992 does, CFA with R-studio showed that the one factor model fitted the data (factor loadings ranged from 0.323 to 0.750 ), its items had $r_{i t-\mathrm{s}}$ that ranged from 0.32 to 0.64 , as a scale had a Cronbach's alpha of 0.84 , showed a concurrent validity coefficient $r=$ $0.23(p<0.01)$ with the RSeS Indonesia as a criterion, and was able to differentiate the levels of ethnic identity of sample pairs of Javanese, Bataks, Dayaks, Chinese, Florinese and a mixture of two or three ethnic groups. Hence, the MEIM Indonesia was conceptually and empirically proven to have construct equivalence with the 1992 MEIM as well as to show adequacy and was coined Skala Identitas Suku Bangsa (SISB).
\end{abstract}

Keywords: ethnic identity; translation-back-translation; construct equivalence; dual identity; hybrid identity

Identity is an implicit or explicit response to the question of "Who are you?" The answer could be at the individual or collective level (Vignoles, Schwartz \& Luyckx, 2011). Discussing identity at the individual level used to be based on Erikson's theory of ego identity and is defined as the feeling of similaritycontinuity as a whole person that one is experiencing and is recognized by others, as well as the feeling of who one is (Erikson, 1968). Discussing identity at the collective level used to be based on Tajfel's (1982) social identity theory which recognizes that identity grows from the feeling of being a member of a group and its accompanying affective experience. The affective experience of being a member of

${ }^{1}$ Address for corespondence: aswignyawardaya@yahoo.co.id a group would constitute one's selfesteem, namely the feeling of one's selfworth (Umana-Taylor, Yazedjian, \& Bamaca-Gomez, 2004). Through the feeling of self-worth, identity serves as a vital element that forms one's life's activity.

\section{Ethnicity}

One kind of group membership which constitutes one's identity is ethnicity (Phinney \& Alipuria, 1987; Suparlan, 2003), namely the group characterization that one has and is recognized by others as having a common ancestry, history, and cultural traits including language, beliefs, values, music, fashion, special cuisine, and place of origin (Cockley, 2007). Ethnicity provides one with an ethnic identity, namely the feeling of being member of a certain ethnic group including self- 
labeling, a feeling of belonging, positive evaluation, knowledge, and involvement in one's ethnic group's activity (Cockley, 2007). Data from the 2010 population census showed that there are at least 633 ethnic groups in Indonesia, the 15 biggest of which include the Javanese, Sundanese, Malays, Bataks, Madurese, Betawis, Minangkabau, Buginese, Bantenese, Banjarese, Balinese, Acehnese, Dayaks, Sasak, and Chinese (Ananta, Arifin, Hasbullah, Handayani, \& Pramono, 2015).

Despite its importance as one form of the grouping of people, research on ethnicity and ethnic identity has been scarce in Indonesia. One apparent cause was the governments' political policies in the past. Both the Old Order (1945-1967) and the New Order (1967-1998) governments contended that public awareness of ethnic composition in Indonesia might well result in socio-political instability (Ananta et al., 2015). Consequently, neither new census data were available nor much research on ethnicity was conducted during those governing eras. Research from anthropology tended to focus on the negative side of ethnicity and prioritize research on culture as a means to build the Indonesian nationalism (Mattulada, 1999). Research from psychology tended to focus on certain ethnic group, such as the application of Javanese values in the practice of management in organizations (Irawanto, Ramsey, \& Ryan, 2012). The Indonesian society is currently facing the challenge of strengthening its sense of nationality as well as developing cultural citizenship as a new form of social bond which is more compatible within the context of cultural plurality not only at the national level but also at the regional and even at the global levels. Ethnic identity may serve as an important cultural capital in negotiating the new demands. Hence, research on ethnic identity is both timely and urgent.

As an initial step in exploring ethnic identity in Indonesia, this research aimed to examine the adequacy of a measure of ethnic identity that has been and is still widely used in multi-racial-multi-ethnic countries, namely the Multigroup Ethnic Identity Measure or shortly called MEIM (Phinney, 1992), using a sample of students with different ethnic backgrounds as participants (Byrd, 2012). The result would be an MEIM in Indonesian language that would be equivalent both conceptually and empirically with the original version so that it would be valid to be applied to the Indonesian youth of different ethnic backgrounds.

\section{Ethnic identity}

Ethnic identity differs from ethnicity. Ethnicity is one's objective status as a member of an ethnic group that she/he acquired in ascriptive manner according to her/his parents' heritage (Suparlan, 2003). Ethnic identity involves one's awareness and subjective recognition of her/his ethnicity. Treating ethnic identity as a psychological construct, Phinney (1992) developed the Multigroup Ethnic Identity Measure (MEIM) to appraise the ethnic identity of adolescents and young adults of different ethnic backgrounds.

Phinney (1989; 2004) used Tajfel's social identity theory, Erikson's ego identity theory, and Marcia's identity status theory as the theoretical bases for MEIM. Following Tajfel, ethnic identity was defined as part of self-concept stemming from the consciousness of being a member of a social group as well as the feelings of worth and meaningfulness attached to that status (Phinney \& Ong, 2007). Ethnic identity comprised six components: (1) self-categorizing/labeling: 
identifying oneself as a member of a certain ethnic group; (2) commitment/ attachment: a feeling of belonging as well as attaching and involving oneself with one's ethnic group; (3) exploration: seeking information and experience related to one's ethnicity; (4) ethnic behavior: doing activities which are the characteristics of one's ethnicity such as speaking local language; (5) ingroup evaluation/attitude: feeling comfortable with and showing positive attitude toward one's ethnic group; and (6) values/beliefs: valuing the values and beliefs that are unique to one's ethnic group.

Eriksonian model of ego-identity development was used to explain the development of ethnic identity (Phinney \& Ong, 2007). According to this model, one's identity develops with age, starting at childhood through observation and reflection and reaches its peak at adolescence/young-adulthood with the acquisition of resolution, namely the acquisition of one's clear and fixed selfidentity. Hence Phinney focused her research with the MEIM on samples of adolescents and young adults with different ethnic backgrounds.

Finally, Marcia's identity status model (1966) was used to operationalize the formation of Eriksonian ego identity. According to this model, identity is formed by two processes: (1) exploration: exploring and experimenting with various beliefs; and (2) commitment: choosing a certain set of beliefs as a guide of one's life. Based on the degree of one's exploration/ commitment to identity, there may be four kinds of identity status: (1) diffusion, indicated by low exploration and low commitment to identity; (2) foreclosure, indicated by low exploration and high commitment to identity; (3) moratorium, indicated by high exploration and low commitment to identity; and (4) achievement, indicated by high exploration and high commitment to identity. Using the three theories Phinney developed the MEIM to measure the commitment to ethnic identity in youth of different ethnic backgrounds (Phinney, 1992; 2004).

\section{Multigroup Ethnic Identity Measure (MEIM)}

The MEIM was developed through four stages: (1) the development of the initital version by Phinney and Ambarsoom in 1987; (2) the development of the first revised version by Phinney and Alipuria in 1990; (3) the development of the second revised version by Lochner and Phinney in 1988; and (4) the development of the third revised version by Phinney in 1992 - hence the name of the 1992 MEIM - that became the early final version and was used by many researchers (Phinney, 1992; Roberts, et al., 1999; Spencer, Icard, Harachi, Catalano, \& Oxford, 2000; Lee \& Yoo, 2004; Phinney \& Ong, 2007; Helms, 2007). The 1992 MEIM consisted of 14 statements uncovering three aspects of ethnic identity (Phinney, 1992; Phinney \& Ong, 2007): (1) positive attitude and sense of belonging to a certain ethnic group, 5 items (e.g. "I am happy that I am a member of the group I belong to"); (2) ethnic identity achievement comprising exploration and achievement, 7 items (e.g. "I have a clear sense of my ethnic background and what it means for me"); (3) ethnic behaviors, 2 items (e.g. "I participate in the cultural practices of my own group such as special food, music, or customs"). Subjects were required to express their agreement to each item in a four-point Likert-type scale from "Strongly agree" to "Strongly disagree". Each response was scored from 4 to 1 for the positively worded statements, or its opposite for the negatively worded ones. The score of each 
subject was the mean of the scores of all items that ranged from 4 (high ethnic identity) to 1 (low ethnic identity). Three open question items were added to uncover the subject's ethnic identity, her/his father's ethnic identity, and her/his mother's ethnic identity. These items were not scored, serving only to get the subject's background information (Phinney, 1992).

Psychometric examinations on the scale's items both individually and as a whole using samples of highs chool students (14-19 years, mean age $=16.5$ years) and college students (18-34 years, mean age $=20.2$ years) of different ethnic backgrounds (Asian Americans, African Americans, Hispanics, Whites, Asians, Blacks mixed backgrounds and other) in the United States showed the following properties (Phinney, 1992). First, the whole scale had reliability coeffiecients between 0.81 (high school sample) and 0.90 (undergraduate sample), the affirmation/ belonging subscale had reliability coefficients between 0.75 (high school sample) and 0.86 (undergraduate sample), and the ethnic-identity achievement subscale had reliability coefficients between 0.69 (high school sample) and 0.80 (undergraduate sample). The reliability of the ethnic behavior subscale could not be calculated due to the number of its items which were only two, but it proved to increase the reliability of the whole scale (Phinney, 1992). Second, the 14 items measuring ethnic identity proved to form one factor and accounted for between 20\% (high school sample) and 30.8\% (undergraduate sample) of the total variance explained. Third, as predicted, ethnic identity as measured by the 1992 MEIM and selfesteem as measured by the Rosenberg SelfEsteem Scale were significantly correlated $(r$ $=0.31, p<0.001$, for the high school sample; $r=0.25, p<0.001$, for the undergraduate sample).

Hence Phinney (1992) concluded as follows. First, the 1992 MEIM as a measure of ethnic identity could be applied to samples of youth with different ethnic backgrounds. Second, at least in samples of high school and undergraduate students, ethnic identity was a single factor consisting of three corrrelated aspects (positive attitudes, identity achievement, and ethnic behaviors). Third, ethnic identity as a psychological construct could be conceptualized as a general phenomenon and could be measured in samples of adolescents and young adults of different ethnic backgrounds with satisfactory reliability. Further research with the 1992 MEIM in general confirmed that ethnic identity as measured by the 1992 MEIM: (1) was a valid psychological construct in samples of adolescents and young adults; (2) had an identifiable structure; (3) could be measured with satisfactory reliability in samples of different ethnic backgrounds; and (4) was able to show different levels of ethnic identity in samples of adolescents and young adults of different ethnic backgrounds (Phinney, 1992).

Other researches found differing evidences regarding the number of factors of the 1992 MEIM. Dropping the two negative items Roberts, et al. (1999) found two factors: social identity (affirmation and belonging) and identity formation (exploration and commitment including ethnic behaviors as parts of exploration). The two factors were highly and positively correlated, hence it was concluded that the 12 items of the 1992 MEIM could be used to measure a global ethnic identity. Cockley (2007) found that the 14 items of the 1992 MEIM represented three correlated aspects of a single factor as indicated by Phinney (1992). On the 
contrary, dropping the two negative items and the two behavioral items, modifying the wording of some items and changing two positive items with new ones, Phinney and Ong (2007) found a new version, the MEIM-R. The MEIM-R consisted of 6 items representing two factors (exploration and commitment) that were positively and highly correlated $(r=0.74)$. Phinney and Ong (2007) concluded that there might still be controversies regarding the number of factors of ethnic identity as measured by the MEIM, but exploration and commitment seemed to be the two key aspects.

Conceptually the weakness of the MEIM-R lied in the reduction of ethnic identity aspects from three (affirmation and belonging, exploration and resolution, and ethnic behaviors) into two (exploration and commitment) that was completely consistent with Erikson's theory while undermining the aspect of social identity. Hence the present researcher decided to use the 1992 MEIM that consisted of 14 items and comprised three aspects, consistent with Eriksonian and Tajfelian theories as well as Phinney's original ideas (1992). This research aimed to examine the equivalence of the ethnic identity construct as measured by the 1992 MEIM with the way students of different ethnic backgrounds in Indonesia were experiencing their ethnic identity. The equivalence was examined by finding out the number of factors in the MEIM Indonesia using exploratory factor analysis and examining the data fit of the model resulting from the exploratory factor analysis using confirmatory factor analysis. The product of this research was an adapted version of the 1992 MEIM in Indonesian language that would have construct equivalence (van de Vijver \& Tanzer, 2004) with the original version in measuring the levels of ethnic identity of samples of adolescents and young adults of different ethnic backgrounds in Indonesia. The measure was expected to have adequacy to be used further in exploring the role of ethnic identity in the formation of both their national and cultural citizenship identities.

\section{Method}

\section{Participants}

The participants were 448 students from 12 study programs in a private university in Yogyakarta. They consisted of 179 (40\%) males and 269 (60\%) females; aged between 17 and 28 years (Mean $=19.87$; SD = 1.30); 56 (13\%) were Moslems, 114 (25\%) were Protestants, 259 (58\%) were Catholics, 8 (2\%) were Buddhists, and 11 (2\%) were Hindus; 254 (57\%) were Javanese, 41 (9\%) were Bataks, 33 (7\%) were Dayaks, $28(6 \%)$ were Chinese, 21 (5\%) were Florinese, $23(5 \%)$ were a mixture of two or three ethnicities, the rest were of other ethnic backgrounds including 5 (1\%) Sundanese, 4 (0.04\%) Sumbese, and $3(0.06 \%)$ Niassians. They were conveniently selected as classes enrolling in certain courses with the permission from the university administration, the assignment of the department chairs, and the consent of the lecturers. The data gathering was conducted September 4 to 26, 2018. From a total of 596 students enrolled in the selected classes, 497 (83\%) were present and filled the questionnaire. From the 497 collected questionnaires, 49 (10\%) were incomplete, hence a total of 448 questionnaires were available for data generation. Verbal informed consent was secured from the participants at the beginning of the data collection activity. A fine ball-pen was awarded to each participant to fill the 
questionnaire and as a token of gratitude for their participation.

\section{Instruments}

The main instrument was the adapted Indonesian version of the Multigroup Ethnic Identity Measure or the MEIM (Phinney, 1992). In this study the original MEIM was the third revised version (Phinney, 1992) and was named the 1992 MEIM and its adapted Indonesian version was named the MEIM Indonesia.

Following Kroger and Marcia (2011), to validate a measure of a psychological construct such as ethnic identity could be done by examining the correlation between the MEIM scores as the operational definition of ethnic identity and a dependent variable conceived to be theoretically relevant. Dependent variables used to validate a measure are usually differentiated into: (a) near variables, comprising those variables conceived to be correlated with the construct under study based on their face validity; and (b) far variables, comprising those variables conceived to be vaguely correlated with the construct under study. The near variable which was conceived as relevant and was commonly used to examine the construct validity of a measure of ethnic identity was self-esteem (Kroger \& Marcia, 2011). The widely used measure of selfesteem was the Rosenberg Self-esteem Scale (Franck et al., 2008; Martin-Albo et al., 2007). Hence a second instrument for this study was the Rosenberg Self-esteem Scale (Rosenberg, 1965) or the RSES. This measure consisted of ten positive and negative statements with a four-point Likert-type scale. Participants were required to indicate their agreement to each item from "Strongly agree" through "Strongly disagree". Scores of 4 to 1 were given to responses to each positive statement, and the reverse was given to responses to each negative statement. The participant's scale score was the sum of her/his score on each item which ranged from 10 to 40. A high score indicated a high level of self-esteem, and the opposite if the score was low. In this study the Rosenberg Self-esteem Scale (Rosenberg, 1965) was adapted into Indonesian and was named the RSeS Indonesia.

The MEIM and the RSeS were adapted into Indonesian using the translation-backtranslation method (Brislin, 1970). The researcher as an Indonesian-English bilinguist translated the MEIM and the RSeS from their source language (English) into the target language (Indonesian). Another bilinguist who was a Ph.D. holder in psychology from an Australian university and was unfamiliar with the two measures back-translated the Indonesian translations of the MEIM and the RSeS into English. The Indonesian translations, the English back-translations as well as the original versions of the MEIM and the RSeS were scrutinized and discussed to ascertain that both the items and the instructions of the MEIM Indonesia and the RSeS Indonesia maintained the meanings of their original versions. With a slight modification on two items (items number 3 and 4) of the Indonesian version of the MEIM, an MEIM Indonesia and an RSeS Indonesia which were conceptually equivalent in meaning with their original versions were obtained. To ascertain that the term ethnicity was understood by Indonesian participants, the researcher consulted to two Ph.D. holders in anthropology from a Dutch university and an American university, and the agreement was reached that the terms "kelompok etnis" (ethnic group) and "suku bangsa" (ethnicity) may interchangeably be used to convey the same meaning. To 
ascertain that the grammar and spelling of the two measures complied with the standards of the Indonesian language, the researcher consulted to an Indonesian linguist.

The try-out forms of the two scales were obtained after some modifications on the settings of the instructions and the items based on the results of a pilot study involving five senior undergraduate students that focused on examining the readability of the instructions, the items, the scale format, and the expected time to complete them. Examination on the psychometric properties of the two scales based on data gathered from 60 students in a private university in Yogyakarta showed that the items of the MEIM Indonesia had discriminating power of $\mathrm{rit}_{\mathrm{i}} \mathrm{S}$ that ranged from 0.329 to 0.795 and as a whole had a Cronbach alpha $=0.850$, while the items of the RSeS Indonesia had discriminating power of $\mathrm{r}_{\mathrm{it}} \mathrm{S}$ that ranged from -0.001 to 0.591 and as a whole had a Cronbach alpha $=0.756$. One of the RSeS Indonesia items (number 8) had a very small and negative $r_{i t}$. Aside from showing a low discriminating power, the negative sign was consistent with the finding of a factor analysis involving participants in 53 countries showing that this item had a negative loading in five countries including Indonesia, hence was named a deviant item (Schmitt \& Allik, 2005). This item would be examined further. Hence, except for the issue with item number 8 of the $R S e S$ Indonesia, there seemed to be an early indication that the two scales had quite good psychometric properties, and so the proper gathering of data could follow.

\section{Analysis}

The main analysis of data consisted of three steps. First, an exploratory factor analysis was conducted on the MEIM
Indonesia to uncover its internal structure and to find out whether it was equivalent with the 1992 MEIM, namely having a single factor. Second, a confirmatory factor analysis was conducted on the MEIM Indonesia to find out if the internal structure revealed by the exploratory factor analysis fitted the data. Third, to obtain an additional evidence regarding the construct validity of the MEIM Indonesia its concurrent validity was examined (Hoyt, Warbasse, \& Chu, 2006) using RSeS Indonesia as the criterion. The exploratory factor analysis of the MEIM Indonesia and examination of the correlation between MEIM Indonesia and RSeS Indonesia were conducted on SPSS, while the confirmatory factor analysis of MEIM Indonesia was conducted on $\mathrm{R}$ Studio using the package of lavaan.

\section{Results}

Examination on the appropriateness of the correlation matrix data to be factor analyzed with the Bartlett test resulted in a $\chi^{2}(d f=91)=1,648.26, p=0.000$ and $K M O=$ 0.884 , meaning that the correlation matrix was not a result of random data and had a "meritorious" or useful value of KMO (Kaiser, 1974), hence the data were factorable namely with the exploratory factor analysis. In the exploratory factor analysis $(N=448)$ on MEIM Indonesia, to identify latent factors in the data, the maximum likelihood extraction method was applied (Kahn, 2006). The determination of the number of factors to be retained was based on the assumption of a single factor (Phinney, 1992) as well as on the data including the percentage of total variance explained by each factor (the higher the better), the size of eigenvalues of each factor (the Kaiser criterion, $\geq 1.00$ ), and the scree plot of the eigenvalues of each factor (above the scree line). 


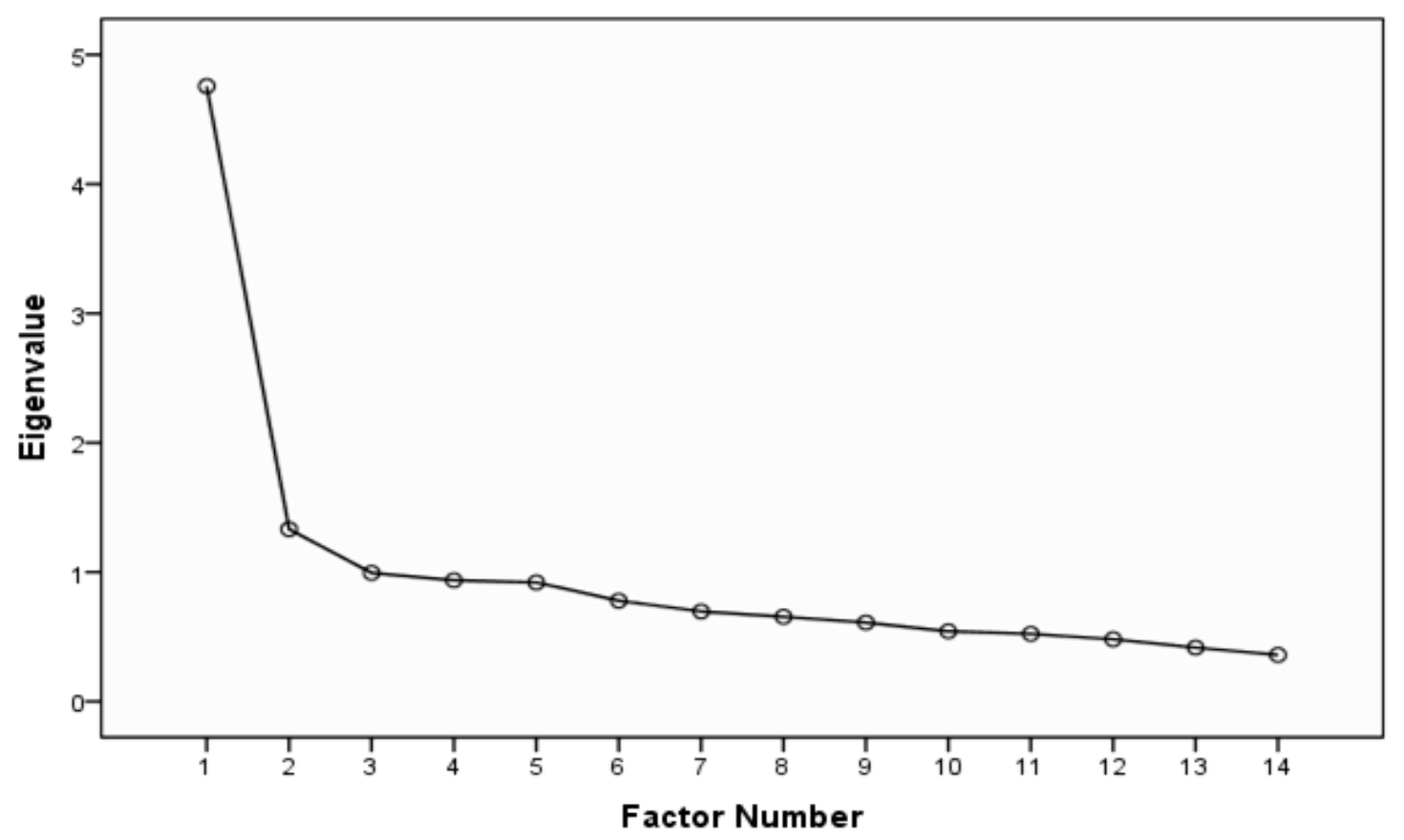

Figure 1. Scree plot of the eigenvalues of each number of factors that might be extracted in MEIM Indonesia.

Results of the exploratory factor analysis were as follows. First, the initial eigenvalues of the factors ranged from 0.360 to 1.332 (Factor 2) and 4.758 (Factor 2) for the two highest ones. Second, based on the observation of the scree plot, the eigenvalues started to flatten at Factor 2 (Figure 1). Third, regarding the $34.263 \%$ of the total variance explained, among the two factors with initial eigenvalues $\geq 1.00$, Factor 1 explained 29.57\% while Factor 2 explained only $4.69 \%$ of it. Fourth, the factor matrix showed that all (14) items had positive and high loadings on Factor 1; two items (number 1 and 7) showed a positive cross loadings on Factor 1 and 2, but only one of them (number 7) showed higher cross loadings on Factor 2 than on Factor 1 (Table 1); being supported by only one item, the evidence was too weak to retain Factor 2 (Worthington \& Whittaker, 2006). Based on the initial assumption as well as the obtained data the decision was made to retain only one factor. Hence, there was some initial indication that MEIM Indonesia was empirically equivalent with the original MEIM (Phinney, 1992) in loading only on one single factor, namely ethnic identity.

The next step was to examine the data fit of the single factor model of MEIM Indonesia resulting from the exploratory factor analysis with confirmatory factor analysis. The estimation of the model was conducted with maximum likelihood model since the goal was to maximize the probability that the observed covariance matrix was derived from the true population (Kahn, 2006). The model fit was evaluated with $\chi^{2}$, Comparative Fit Index (CFI), Tucker-Lewis Index (TLI), Root Mean Square Error Approximation (RMSEA), and Standardized Root MeanSquared Residual (SRMR). Results of the confirmatory factor analysis were presented in Table 2. 
ETHNIC IDENTITY: A STUDY OF CONSTRUCT EQUIVALENCE

Table 1.

Factor Matrix of the MEIM Indonesia Extracted with the Maximum Likelihood Method

\begin{tabular}{|c|c|c|c|c|c|c|c|c|c|c|c|c|c|c|c|}
\hline & & \multicolumn{14}{|c|}{ Item } \\
\hline & & 1 & 2 & 3 & 4 & 5 & 6 & 7 & 8 & 9 & 10 & 11 & 12 & 13 & 14 \\
\hline \multirow{2}{*}{ Factor } & 1 & 0.512 & 0.343 & 0.505 & 0.374 & 0.573 & 0.323 & 0.342 & 0.642 & 0.585 & 0.589 & 0.609 & 0.556 & 0.750 & 0.688 \\
\hline & 2 & 0.391 & 0.040 & 0.306 & -0.037 & -0.160 & 0.215 & 0.376 & -0.028 & -0.007 & 0.211 & -0.173 & 0.087 & -0.187 & -0.276 \\
\hline
\end{tabular}

Table 2.

Indices of the Fit of the Single Factor Model of the MEIM Indonesia with Data Resulting from a First Order Confirmatory Factor Analysis.

\begin{tabular}{cllll}
\hline No & \multicolumn{1}{c}{ Fit Indices } & Results & Criteria & \multicolumn{1}{c}{ Decision $^{*}$} \\
\hline 1 & $\chi^{2}(d b=77 ; p<0.01)$ & Significant & Non-sig. & Non-acceptable \\
2 & CFI & 0.875 & $\geq 0.950$ & Non-acceptable \\
3 & TLI & 0.853 & $\geq 0.950$ & Non-acceptable \\
4 & RMSEA & 0.086 & $\leq 0.08$ & Acceptable \\
5 & SRMR & 0.059 & $\leq 0.05$ & Acceptable \\
\hline
\end{tabular}

*Based on the criteria of Schermelleh-Engel, Moosbrugger, \& Muller (2003).

Three $\left(\chi^{2}, \mathrm{CFI}\right.$, and TLI) of the five indices showed that the single factor model of MEIM Indonesia did not fit the data. Since the sample was large enough $(N=448)$, the $\chi^{2}$ that was significant might represent the sample size more than the data unfit of the model, hence it was ignored. The RMSEA and SRMR showed that the single factor model of MEIM Indonesia fitted in the sense of showing an acceptable fit (Schermelleh-Engel, Moosbrugger, \& Muller, 2003) with data. Since the single factor model was consistent with Phinney's (1992) assumption, it was concluded that there was enough evidence that the MEIM Indonesia was theoretically and empirically equivalent in the sense of having a construct equivalence (van de Vijver \& Tanzer, 2006) with the original MEIM. The single factor model resulting from the first order confirmatory factor analysis was visually presented in Figure 2.

To increase the evidence of the validity of MEIM Indonesia the following four data were presented. First, reexamination of the quality of the MEIM
Indonesia based on the research data showed that its items had discriminating power of $\mathrm{rit}_{\mathrm{S}} \mathrm{S}=0.319-0.644$ and as a whole had a Cronbach alpha $=0.837$. Second, reexamination of the quality of $R S e S$ Indonesia based on the research data showed that its items had discriminating power of $r_{i t}$ - $=-0.033-0.629$ and as a whole had a Cronbach alpha $=0.762$. Although still having a deviant item (number 8) which was consistent with other findings (Schmitt \& Allik, 2005), the RSeS Indonesia proved to be psychometrically good enough. Concurrent validation showed that MEIM Indonesia and RSeS Indonesia were positively and significantly correlated $(r=0.23 ; p<0.01)$. This correlation coefficient was consistent with the finding of Phinney (1992) which showed that the correlation between the MEIM and the RSeS in samples of students was $r=0.25(p<0.01)$. Third, $23(5 \%)$ of the 448 participants with parents of different ethnic backgrounds labelled themselves as mixture of their parents' ethnicities. They were categorized as having a mixed ethnic background and were predicted as having 


\section{SUPRATIKNYA}

a lower degree of ethnic identity (Mean = 3.01; $S D=0.39$ ) than those with specific ethnic backgrounds (Mean $=3.04 ; S D=$ $0.36)$. The prediction was confirmed but the difference was not significant $(t=0.383$; $p>0.05)$. Fourth, examination on the mean differences of ethnic identity between pairs of the six largest ethnic samples (Javanese, Bataks, Dayaks, Chinese, Florinese, and Mixed) showed significant differences of levels of ethnic identity between the Javanese (Mean $=3.02, S D=$ 0.33 ) and the Dayaks (Mean $=3.20, S D=$
0.37; $t=2.53, p=0.01)$, between the Javanese and the Chinese (Mean $=2.89, S D$ $=0.25 ; t=2.5, p=0.01)$, between the Chinese and the Bataks (Mean $=3.11, S D=$ $0.36 ; t=3.08, p<0.01)$, between the Chinese and the Dayaks (Mean $=3.20, S D=$ $0.37 ; t=3.96, p<0.01)$, between the Chinese and the Florinese (Mean $=3.10, S D=0.32 ; t$ $=2.43, p=0.02)$, and between the Dayaks and the Mixed (Mean $=3.01, S D=0.39), t=$ 1.67) although significant only at $p=0.10$ (Table 3).

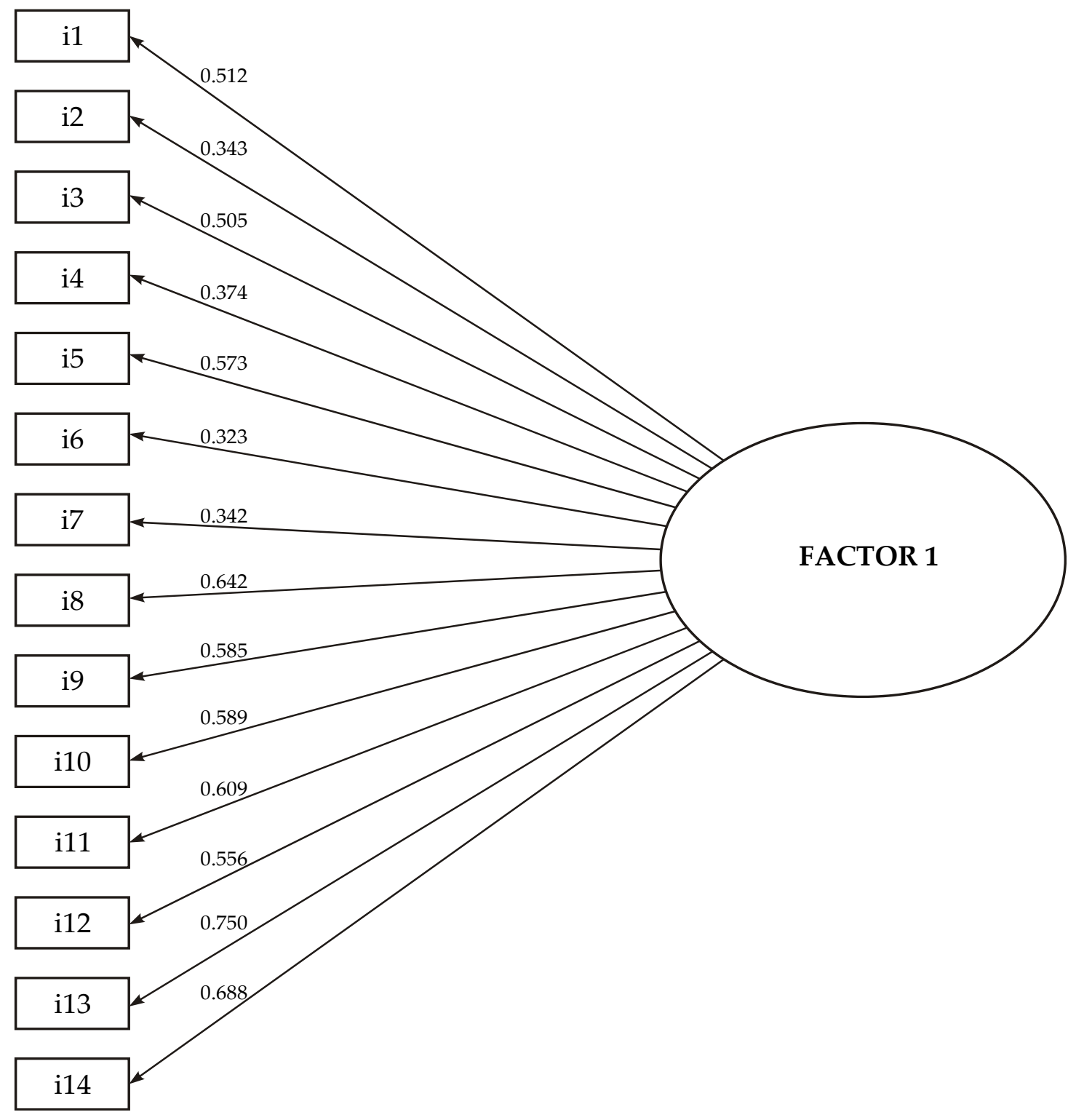

Figure 2. A single factor model of the MEIM Indonesia resulting from a first order confirmatory factor analysis 
Table 3.

$\mathrm{t}$ Tests on Differences of Means of Ethnic Identity between Pairs of the Six Largest Ethnic Samples

\begin{tabular}{llccccccccc}
\hline & & $n$ & Mean & $S D$ & $\mathbf{1}$ & $\mathbf{2}$ & $\mathbf{3}$ & $\mathbf{4}$ & $\mathbf{5}$ & $\mathbf{6}$ \\
\hline 1 & Javanese & 254 & 3.02 & 0.33 & - & & & & & \\
2 & Bataks & 41 & 3.11 & 0.36 & $\begin{array}{c}1.52 \\
(0.13)\end{array}$ & - & & & & \\
& & & & & & & & & \\
3 & Dayaks & 33 & 3.20 & 0.37 & $\begin{array}{c}2.53 \\
(0.01)^{*}\end{array}$ & $\begin{array}{c}0.99 \\
(0.33)\end{array}$ & - & & & \\
& & & & & & & & & \\
4 & Chinese & 28 & 2.80 & 0.25 & 3.08 & 3.97 & - & & \\
& & & & $(0.01)^{*}$ & $(0.00)^{*}$ & $(0.002)^{*}$ & - & & \\
5 & Florinese & 21 & \multirow{2}{*}{3.10} & 0.32 & 0.99 & 0.20 & 1.07 & 2.43 & - & \\
& & & & $(0.32)$ & $(0.84)$ & $(0.29)$ & $(0.02)^{*}$ & - & \\
6 & Mixed & 23 & \multirow{2}{*}{3.01} & 0.39 & 0.10 & 1.02 & 1.67 & 1.35 & 0.77 & - \\
& & & & $(0.92)$ & $(0.31)$ & $(0.10)^{* *}$ & $(0.18)$ & $(0.44)$ & \\
\hline
\end{tabular}

*Significant at $p=0.00-0.02 ;{ }^{* *}$ significant at $p=0.10$.

\section{Discussion}

The results showed that MEIM Indonesia had a satisfactory construct equivalence with the 1992 MEIM, had quite good psychometric properties, had concurrent validity with the RSeS Indonesia, and could indicate level differences of ethnic identity between pairs of samples of the Javanese, Bataks, Dayaks, Chinese, Florinese, and a mixture of two ethnic groups. The conclusion was that the MEIM Indonesia was equivalent with the 1992 MEIM and was useful to explore the ethnic identity of samples of youth with different ethnic backgrounds in Indonesia. This information could be used as a basis in understanding the dynamics of both intra and inter-ethnic group relations in Indonesia. For the sake of convenience in communication, the MEIM Indonesia was named the Skala Identitas Suku Bangsa or the SISB.

One of the limitations of this research was the size and source of samples that came from only a single higher learning institution. Besides, placed within the discourse of both social identity in particular as well as identity in general, there were four issues worth to scrutinize.
First, the existence of a group that labelled itself as having a mixed ethnic identity among those participants with parents of different ethnic groups. Mixed identity could be interpreted as hybrid identity (Yazdiha, 2010), but the process and the implications of the formation of this kind of identity was beyond the scope of both Eriksonian and Tajfelian theories on which the SISB was based. Second and regarding the issue of mixed identity, for citizens of a unitary country with hundreds of ethnic groups such as Indonesia (Ananta et al., 2015), ethnic identity was one of the elements in the formation of a superordinate group identity that was even more important, namely the Indonesian national identity. The concept of ethnic identity as measured by SISB did not include the aspect of social-cultural integration implicated in the concept of dual identity (Leszczensky \& Grabs Santiago, 2015) as members of both a certain ethnic group and a nation at the same time that the Indonesian youth were actually facing. Third, historically, the concept of ethnic identity was rooted in the tradition of culture study conducted by researchers of other social-humanity disciplines. To be able to make contributions in the 
understanding of the formation of the real "way of living" and "way of thinking" of youth as both members of a certain ethnic group and Indonesian nation, psychology could not work alone without benefitting the ideas of researchers from other sister disciplines (Ponterotto \& Park-Taylor, 2007). The concept of ethnic identity derived from Eriksonian and Tajfelian theories basically followed the biological paradigm (Hall, 1996) that viewed the individual as self-contained with a capacity to think-realize-act centered on a mental core that grew for the first time at birth. Although it developed through social interaction, this mental core was essentially continuous and identical throughout one's life span. An alternative paradigm is supposed to be able to offer more contextual explanations on the phenomenon of identity was the postmodern paradigm that rejected the notion of an essential and permanent identity that was biologically acquired. Rather, the human identity was conceived as historically acquired in accordance with the way one's presence was recognized by various enclosing cultural systems. When those enclosing cultural systems grew more complex, one would be exposed to an unlimited number of possible identities from which she/he could choose one at least temporarily. An individual could present different identities at different occasions, freed from the domination of a single permanent identity (Hall, 1996).

\section{Conclusion}

This research aimed at examining the usefulness of the Multigroup Ethnic Identity Measure (the 1992 MEIM) to explore the ethnic identities of youth in Indonesia. The result was the Skala Identitas Suku Bangsa (SISB) which was the Indonesian adaptation of the 1992 MEIM that was conceptually and empirically equivalent with the original version.

\section{Recommendation}

To improve it and based on the discussion, three agendas were worth to do as followups of this research: (1) to widen the data base to increase the usefulness of SISB for utilization to samples of youth with more diverse ethnic backgrounds in Indonesia; (2) to explore mixed identities as both hybrid and dual identities in relation to the fact that most Indonesian young people were members of certain ethnic groups as well as members of the Indonesian nation; and (3) to explore the usefulness of the post-modern paradigm in explaining the dynamics of the identity formation of members of the Indonesian society based on cultural systems other than ethnicity such as religion (Tri Subagya, 2015), political affiliation, and other systems of cultural significations.

\section{Acknowledgment}

This research was funded with an internal grant from the Sanata Dharma University Institue for Research and Service to Communnity. The author wished to extend his gratitude to Agung Santoso, Ph.D. for his assistance as consultant in conducting the confirmatory factor analysis using the R-Studio as well as in giving a preliminary review on the early version of this manuscript.

\section{References}

Ananta, A., Arifin, E. N., Hasbullah, M. S., Handayani, N. B., \& Pramono, A. (2015). Demography of Indonesia's ethnicity. Singapore: Institute of East Asian Studies. doi: 10.1080/14631369.2016.1249653 
Brislin, R. W. (1970). Back-translation for cross-cultural research. Journal for Cross-Cultural Psychology, 1(3), 185-216. doi: $10.1177 / 135910457000100301$

Byrd, C. M. (2012). The measurement of racial/ethnic identity in children. A critical review. Journal of Black Psychology, 38(1), 3-31. doi: $\underline{10.1177 /}$ $\underline{0095798410397544}$

Cokley, K. (2007). Critical issues in the measurement of ethnic and racial identity: A referendum on the state of the field. Journal of Counseling Psychology, 54(3), 224-234. doi: $10.1037 /$ 0022-0167.54.3.224

Erikson, E. (1968). Identity youth and crisis. New York: W.W. Norton.

Franck, E., De Raedt, R., Barbez, C., \& Rosseel, Y. (2008). Psychometric properties of the Dutch Rosenberg Self-esteem Scale. Psychologica Belgica, 48(1), 25-35. doi: 10.5334/pb-48-1-25

Hall, S. (1996). The question of cultural identity. Dalam S. Hall, D. Held, D. Hubert, \& K. Thompson. (Eds.), Modernity. An introduction to modern societies (h. 274-314). Hoboken, NJ: Wiley-Blackwell.

Helms, J. E. (2007). Some better practices for measuring racial and ethnic identity constructs. Journal of Counseling Psychology, 54(3), 235-246. doi: $\underline{10.1037 / 0022-0167.54 .3 .235}$

Hoyt, W. T., Warbasse, R. E., \& Chu, E. Y. (2006). Construct validation in counseling psychology research. The Counseling Psychologist, 34(6), 769-805. doi: $\underline{10.1177 / 0011000006287389}$

Irawanto, D. W., Ramsey, P. L., \& Ryan, J. C. (2012). Challenge of leading in Javanese culture Asian Ethnicity, 12(2). 125-139. doi: 10.1080/14631369.2011. $\underline{571829}$
Kahn, J. H. (2006). Factor analysis in counseling psychology research, training, and practice: Principles, advances, and applications. The Counseling Psychologist, 34(5), 684-718. doi: $\underline{10.1177 / 0011000006286347}$

Kaiser, H. F. (1974). An index of factorial simplicity. Psychometrika, 39(1), 31-36. doi: $\underline{10.1007 / B F 02291575}$

Kroger, J., \& Marcia, J. E. (2011). The identity statuses: Origins, meanings, and interpretation. Dalam S.J. Schwartz, K. Luyckx, \& V.L. Vignoles (Eds.), Handbook of identity theory and research (h. 31-53). New York: Springer.

Lee, R. M., \& Yoo, H. C. (2004). Structure and measurement of ethnic identity for Asian American college students. Journal of Counseling Psychology, 52, 3644. doi: $\underline{10.1037 / 0022-0167.51 .2 .263}$

Leszczensky, L., \& Grabs Santiago, A. (2015). The development and test of a measure of youth's ethnic and national identity. Methods, Data, Analysis, 9(1), 87-110. doi: $10.12758 /$ mda.2015.003

Marcia, J. (1966). Development and validation of ego-identity status. Journal of Personality and Social Psychology, 3, 551-558. doi: 10.1037/ $\underline{\mathrm{h} 0023281}$

Martin-Albo, J., Nunez, J. L., Navarro, J. G., \& Grijalvo, F. (2007). The Rosenberg Self-Esteem Scale: Translation and validation in university students. The Spanish Journal of Psychology, 10(2), 458-467. doi: $\underline{10.1017 / S 1138741600006727}$

Mattulada, H. A. (1999). Kesukubangsaan dan negara kebangsaan di Indonesia. Prospek budaya politik abad ke-21. Antropologi Indonesia, 58, 5-12. doi: 10.7454/ai.v0i58.3361

Phinney, J. S. (1989). Stages of ethnic development in minority group 
adolescents. Journal of Early Adolescents, 9, 34-49. doi: 10.1177/ $\underline{0272431689091004}$

Phinney, J. S. (1992). The Multigroup Ethnic Identity Measure. A new scale for use with adolescents and young adults from diverse groups. Journal of Adolescent Research, 7(2), 156-176. doi: $\underline{10.1177 / 074355489272003}$

Phinney, J. S. (2004). Ethnic identity. Developmental and contextual perspectives. Unpublished paper.

Phiney, J. S., \& Alipuria, L. L. (1987). Ethnic identity in older adolescents from four ethnic groups. Paper presented at the Biennial Meeting of the Society for Research in Child Development, Baltimore, MD. ERIC Number: ED283058

Phinney, J. S., \& Ong, A. D. (2007). Conceptualization and measurement of ethnic identity. Current status and future directions. Journal of Consulting Psychology, 54(3), 271-281. doi: 10.1037/ 0022-0167.54.3.271

Ponterotto, J. G., \& Park-Taylor, J. (2007). Racial ethnic identity theory, measurement, and research in counseling psychology: Present status and future directions. Journal of Counseling Psychology, 54(3), 282-294. doi: $10.1037 /$ 0022-0167.54.3.282

Roberts, R. E., Phinney, J. S., Masse, L. C., Chen, Y. R., Roberts, C. R., \& Romero, A. (1999). The structure of ethnic identity of young adolescents from diverse ethnocultural groups. Journal of Early Adolescence, 19(3), 301-322. doi: $\underline{10.1177 / 0272431699019003001}$

Rosenberg, M. (1965). Society and the adolescent self-image. Princeton, NJ: Princeton University Press. doi: $\underline{10.2307 / 2575639}$

Schermelleh-Engel, K., Moosbrugger, H.,
\& Muller, H. (2003). Evaluating the fit of structural equation models: Tests of significance and descriptive goodnessof-fit measures. Methods of Psychological Research Online, 8(2), 2374.

Schmitt, D. P., \& Allik, J. (2005). Simultaneous administration of the Rosenberg Self-Esteem Scale in 53 nations: Exploring the universal and culture-specific features of global selfesteem. Journal of Personality and Social Psychology, 89, 623-642. doi: $\underline{10.1037 /}$ $\underline{0022-3514.89 .4 .623}$

Spencer, M. S., Icard, L. D., Harachi, T. W., Catalano, R. F., \& Oxford, M. (2000). Ethnic identity among monoracial and multiracial early adolescents. Journal of Adolescence, 20(4), 365-387. doi: $\underline{10.1177 / 0272431600020004001}$

Suparlan, P. (2003). Bhineka Tunggal Ika: Keanekaragaman sukubangsa atau kebudayaan? Antropologi Indonesia, 72, 24-37. doi: $10.7454 / a i . v 0 i 72.3472$

Tajfel, H. (1982). Social psychology of intergroup relations. Annual Review of Psychology, 33, 1-39. doi: $\underline{10.1146 /}$ annurev.ps.33.020182.000245

Tri Subagya, Y. (2015). Support for ethnoreligious violence in Indonesia. Yogyakarta: Sanata Dharma University Press.

Umana-Taylor, A. J., Yazedjian, A., \& Bamaca-Gomez, M. (2004). Developing the Ethnic Identity Scale using Eriksonian and social identity perspectives. Identity. An International Journal of Therory and Research, 4(1), 938. doi: $10.1207 / \mathrm{s} 1532706 x i d 04012$

van de Vijver, F., \& Tanzer, N. K. (2004). Bias and equivalence in cross-cultural assessment: An overview. Revue Europeenne de Psychologie Appliquee, 54, 119-135. doi: 10.1016/j.erap.2003.12.004 
Vignoles, V. L., Schwartz, S. J., \& Luyckx, K. (2011). Introduction: Toward an integrative view of identity. Dalam S.J. Schwartz, K. Luyckx, \& V.L. Vignoles (Eds.), Handbook of identity theory and research (h. 1-27). New York: Springer.

Worthington, R. L., \& Whittaker, T. A. (2006). Scale development research. A content analysis and recommendations for best practices. The Counseling Psychologist, 34(6), 806-838. doi: $10.1177 / 0011000006288127$

Yazdiha, H. (2010). Conceptualizing hybridity: Deconstructing boundaries through the hybrid. Formations, 1(1), 31-38. 